\title{
Extension of residue retention increases net greenhouse gas mitigation in China's croplands
}

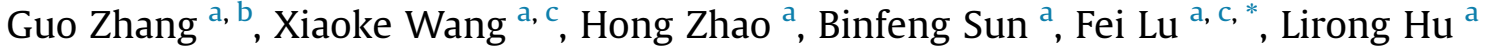 \\ a State Key Laboratory of Urban and Regional Ecology, Research Center for Eco-Environmental Sciences, Chinese Academy of Sciences, Beijing 100085, China \\ ${ }^{\mathrm{b}}$ Institute of Karst Research, Guizhou Normal University, Guiyang 550001, China \\ c Joint Center for Global Change Studies, Beijing 100875, China
}

\section{A R T I C L E I N F O}

\section{Article history:}

Received 30 September 2015

Received in revised form 7 July 2017

Accepted 9 July 2017

Available online 14 July 2017

Handling Editor: Cecilia Maria Villas Boas de Almeida

\section{Keywords:}

Methane emissions

Mitigation potential

Nitrous oxide

Realized mitigation

Residue retention

Soil carbon sequestration

\begin{abstract}
A B S T R A C T
Crop residue retention plays an important role in greenhouse gas (GHG) mitigation for global agriculture. To clarify the current status of residue retention and burning as well as the contribution of these processes to GHG dynamics, we conducted a nationwide survey on residue management in China in 2011 and improved the Carbon Accounting and Net Mitigation of Straw return model with updated param-

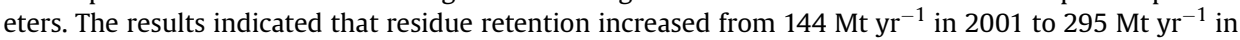
2011, whereas burned residue reached $200 \mathrm{Mt} \mathrm{yr}^{-1}$ in China. Because of these increases in residue retention, the net mitigation related to residue retention increased from $5.3 \mathrm{Tg} \mathrm{Ce}$ in 2001 to $13.3 \mathrm{Tg} \mathrm{Ce}$ in 2011. Further extension would sequester $15.8 \mathrm{Tg}$ C, which is equivalent to a reduction in emissions of 3.9 $\mathrm{Tg}$ Ce from residue burning and a mitigate potential of 3.1 Tg Ce from replacing $1.5 \mathrm{Mt}$ of nitrogen fertilizer. However, the national net mitigation from residue retention would achieve only $45-64 \%$ of the total soil $\mathrm{C}$ sequestration. The spatial heterogeneity of cropping systems and residue management was determined to have different effects on GHG dynamics. The net mitigation would have a negative value in eight provinces because of incremental increases in methane emissions from rice paddies. Increases in residue retention in the remaining 23 provinces would result in a maximum mitigation potential of $10 \mathrm{Tg}$

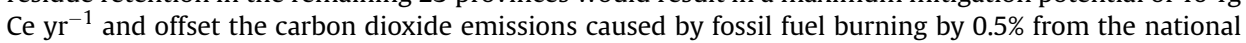
value in 2011. Therefore, residue retention has mitigated a substantial amount of GHGs, and extending this strategy has considerable mitigation potential for China's croplands. Our results indicate that the retention and burning of crop residues have an effect on the GHG dynamics in China and represent potential strategies for mitigating climate change via residue management.
\end{abstract}

๑) 2017 Elsevier Ltd. All rights reserved.

\section{Introduction}

Reducing greenhouse gas (GHG) emissions and enhancing GHG sinks for climate change mitigation represent global challenges (Lal, 2004a). Agricultural production directly contributes to soil organic carbon (SOC) losses and anthropogenic GHG emissions (Smith, 2012). The carbon (C) lost from China's croplands from 1850 to 2000 was estimated at $5.86 \mathrm{Pg} \mathrm{C}$ (Houghton, 2002). Furthermore, the uplands of China emitted 3.0 Pg Ce (100-yr time horizon) of nitrous oxide $\left(\mathrm{N}_{2} \mathrm{O}\right)$, and rice paddies emitted 3.1 Pg Ce of methane $\left(\mathrm{CH}_{4}\right)$ between 1961 and 2005 (Tian et al., 2011). The considerable C

\footnotetext{
* Corresponding author. 18 Shuangqing Road, Haidian District, Beijing 100085, China.

E-mail address: feilu@rcees.ac.cn (F. Lu).
}

loss and current GHG emissions indicate that proper cropland management in China has a significant GHG mitigation potential (Lal, 2004b) because such management, including residue retention, recommended fertilization schedules and no-till farming, can mitigate atmospheric GHG levels by reducing emissions and sequestering $C$ in biomass and soil (Jin et al., 2014).

The management of crop residues affects the $C$ and nitrogen $(N)$ cycles on croplands (Liu et al., 2014). In China, residue burning has been widely adopted during harvesting for faster removal with lower associated costs (Shi et al., 2014). In 2001, residue burning in

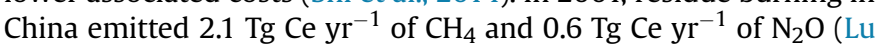
et al., 2010a). Residue retention not only mitigates GHG emissions but also improves soil C sinks (Petersen et al., 2013; Zhao et al., 2014). Furthermore, residue retention can act as a substitute for synthetic $\mathrm{N}$ fertilizers (Gentile et al., 2009), thereby mitigating GHG emissions from $\mathrm{N}$ fertilizer production. However, residue retention 
has also been found to increase $\mathrm{CH}_{4}$ emissions from rice paddies (Cheng et al., 2014) as well as GHG emissions because of the additional fuel used for tilling and ploughing (Lu et al., 2010b). Therefore, all of these factors must be considered when estimating the net effects of residue retention on GHG emissions.

Several studies have focused on the GHG dynamics of residue retention in China. Using the Straw Return and Burning Model (SRBM) and provincial residue utilization information from 2001, the net mitigation potential (NMP) obtained by replacing residue burning with residue retention at the provincial scale was $6.3 \mathrm{Tg} \mathrm{Ce}$ $\mathrm{yr}^{-1}$ (2010a), whereas when all residue from nine crops (e.g., rice, wheat, corn, sorghum, potato, rapeseed, sunflower, cotton and sugarcane) cultivated across China's croplands was returned, the

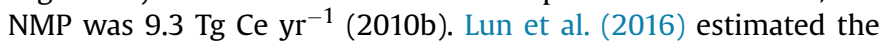
combined effect of performing fertilizer substitution with manure, residue retention, and conservation tillage on $\mathrm{C}$ mitigation in rice, wheat and corn in 2008 and generated a mitigation target set for 2020 in China. However, in these studies, the scenario settings and parameters were based on the published literature rather than on first-hand information from systematic surveys, or they did not consider non- $\mathrm{CO}_{2}$ GHG in the mitigation estimations.

China accounts for the third largest area of croplands in the world. The total residue product on China's cropland increased from 660 to $807 \mathrm{Mt} \mathrm{yr}^{-1}$ between 2000 and 2009 (Jiang et al., 2012), whereas the use of residue as fuel decreased following economic development (Yao et al., 2012). Furthermore, Chinese governmental policies have been implemented to encourage the comprehensive utilization of crop residues (MEP, 1999; MOA, 2007). We hypothesized that these factors would stimulate an increase in the implementation of residue retention, which would affect the GHG budget of residue retention and burning. Our objectives were to (1) clarify the current status of residue retention and burning; (2) analyze the dynamics of realized net mitigation (RNM) of residue retention over the past decade; and (3) estimate the NMP under a full extension of residue retention in place of residue burning on China's croplands in 2011. To achieve these objectives, we conducted a nationwide survey of farmers between 2012 and 2013. By addressing these objectives, we can clarify the contributions of residue retention to GHG mitigation on China's croplands.

\section{Materials and methods}

We considered nine crops in China for this study: rice, wheat, corn, sorghum, potato, rapeseed, sunflower, cotton and sugarcane. The nine crops represent the main cereal or economic crops in China. The residue from other crops is typically used as forage or fuel because of the higher nutrient content or caloric content. The harvested area of these crops accounted for $67 \%$ of the total harvested area in China in 2011 (NBS, 2012).

\subsection{Study region}

In this study, Chinese croplands were divided into four cropping regions according to the heterogeneity of climate, cropping system and cultivation (Lu et al., 2009): northeast, north, northwest and south (Fig. 1). The cropping systems mainly involved one single crop per year in northeastern and northwestern China, doublecropping systems in northern China, and double or even triple cropping in southern China.

\subsection{Field survey}

From 2012 to 2013, we conducted a field survey of farmers on cropland management practices implemented in 2011 in 31
Chinese provinces (Fig. 1). The survey process involved a pilot survey, interviewer training, a formal survey and data entry and cleaning. This survey process is described in detail in Zhang et al. (2016). The survey included questions on the crop species and the percentage of croplands with residue retention and burning. In addition, triangulation questions were included on crop yields, residue retention types, and farmer attitudes toward residue retention, which were designed to ensure the questionnaire validity. We evaluated 752 valid farmer questionnaires, which included 1126 questionnaires from different crop seasons. The invalid questionnaires were those without any residue management or a sum of the percentage of all residue management practices that was more than 100 . In addition, we conducted a survey on equipment use and the resulting fossil fuel consumption during cropland management from specialized agricultural machinery. Additionally, we obtained 40 valid questionnaires on machinery practices in China.

\subsection{Data sources}

In this study, the harvested area, cropland area and yield of the nine studied crops in 2001 and 2011 were obtained from the Chinese Statistical Yearbook from 2002 (NBS, 2012) and 2012 (NBS, 2012), respectively. The percentage of cropland with residue retention (PR) and burned residue (PB) in 2001 was obtained from studies by Lu et al. (2009) and Cao et al. (2008), and those for 2011 were obtained from the field survey.

Multiple cropping systems are widespread on China's croplands. In single-cropping systems, the harvested area equals the cropland area, whereas in multiple cropping systems, the harvested area is double or triple the size of the cropland area. The study area focused on cropland area that cultivated the nine studied crops $\left(A_{i}\right)$, and it was calculated using formula 1 (Lu et al., 2009):

$A_{i}=T C A_{i} \cdot\left(\sum H A_{i j}\right) / T H A_{i}$

where $\mathrm{TCA}_{i}$ represents the total cropland area of all crops in province $i$; $\mathrm{HA}_{i j}$ represents the harvested area of crop $j$ (rice, wheat, corn, sorghum, potato, rapeseed, sunflower, cotton and sugarcane) in province $i$; and $\mathrm{THA}_{i}$ represents the total harvested area of all crops in 2011 province $i$ (NBS, 2012). All areas have a unit of $10^{3}$ ha.

\subsection{Estimation of the GHG dynamics of residue retention and burning}

We improved the SRBM model (Lu et al., 2010b) with a C Accounting and Net Mitigation of Straw return (CANM-Straw) model to inventory the GHG budget from residue retention and burning (Fig. 2). Both the CANM-Straw and SRBM include three parts: input, process and output. With the input of $P R$ and $P B$, the models incorporated the effects of residue treatments when estimating the total effective GHG emissions (TEGEs) and subsequently determined the RNM and NMP generated via extension of residue retention (Fig. 2).

\subsubsection{Inputs}

The PR and PB from five scenarios were required to estimate the RNM for 2001 and determine the RNM and NMP for 2011. These treatments included the following: actual scenarios from 2001 to 2011, hypothetical scenarios for full burning in 2001 and 2011, and a hypothetical scenario for full retention in 2011. The sum of the PR and PB in the actual situation equaled either the PB under a full burning scenario or the PR under a full retention scenario. 


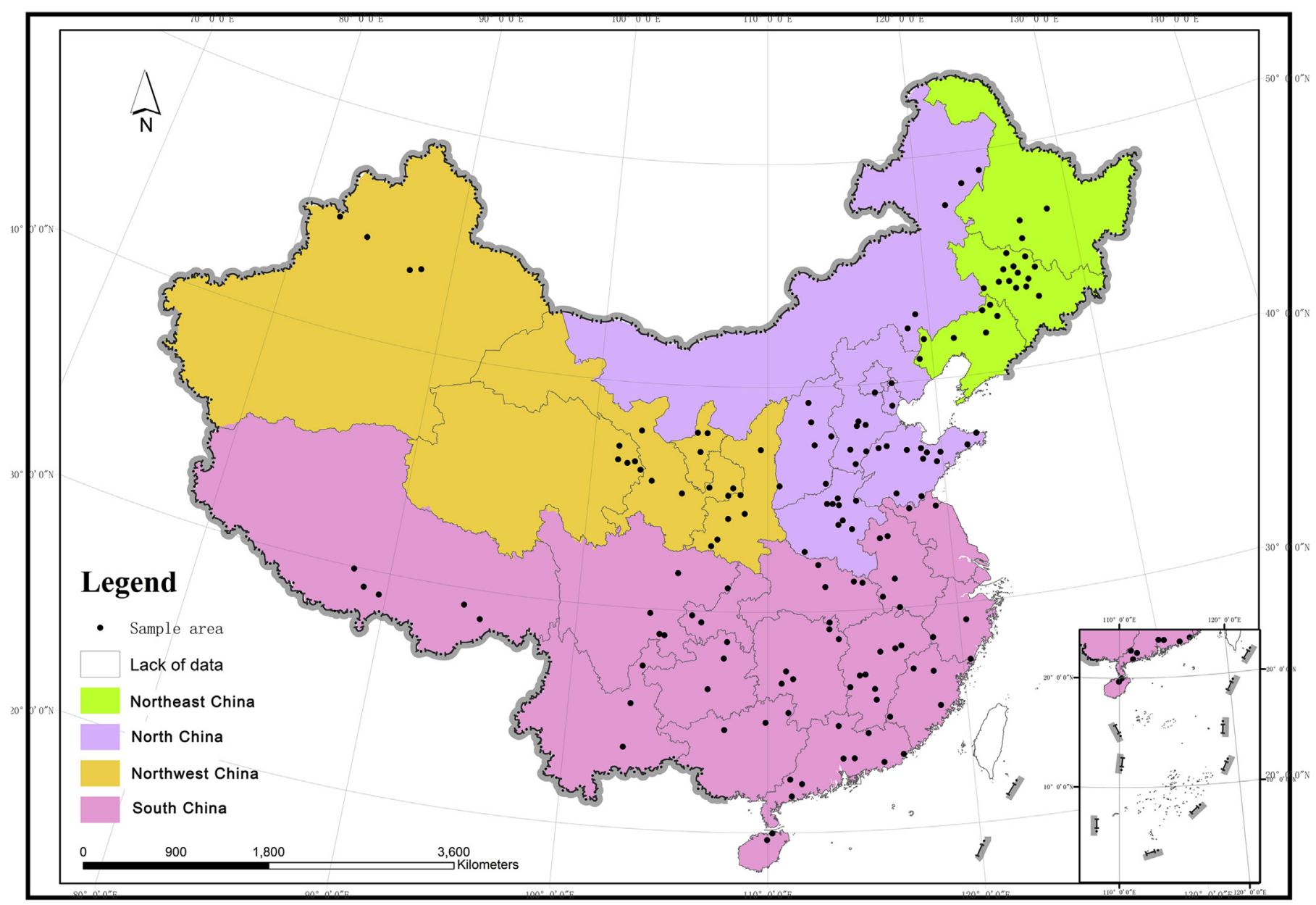

Fig. 1. Map of the study area showing the distribution of surveyed counties.

Input

Process

Output

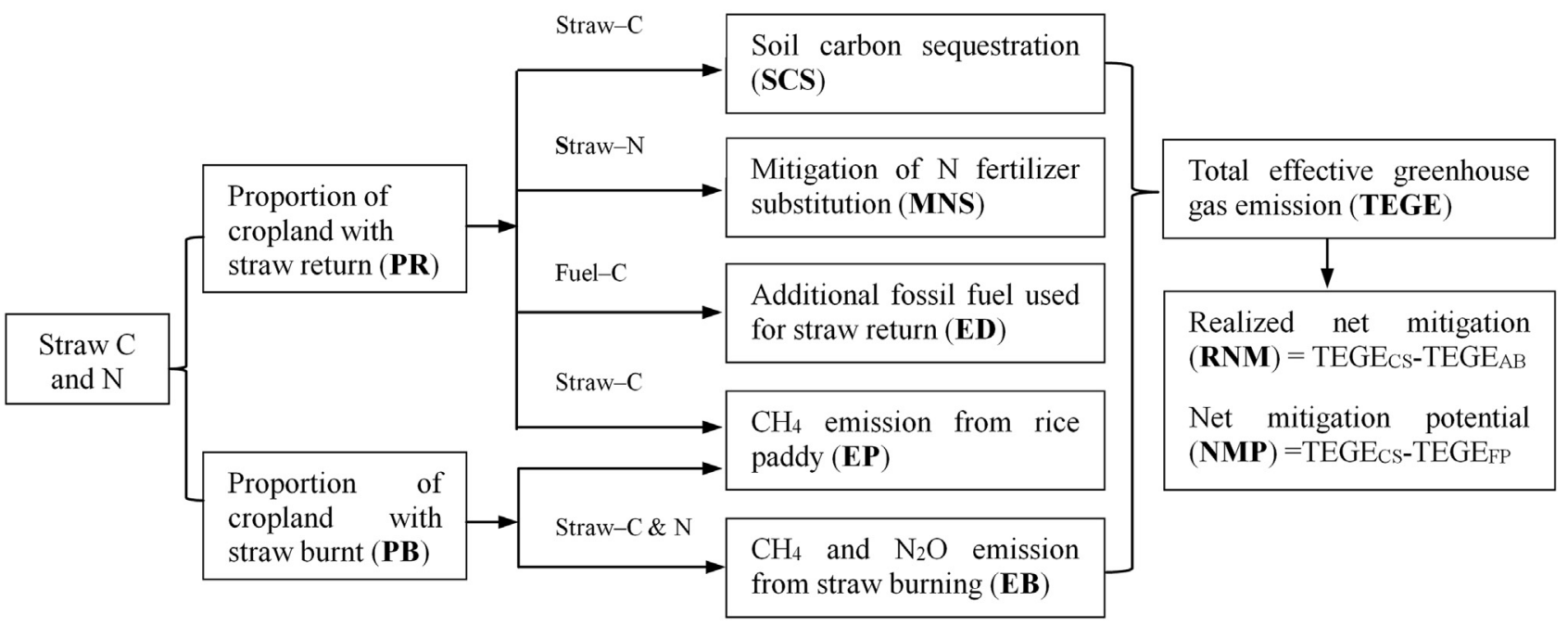

Fig. 2. Structure of the carbon (C)- and nitrogen (N)-oriented Straw Return and Burning Model-II revised from Lu et al. (2010a).

The actual PR and PB in 2001 were obtained from studies Lu et al. (2009), which was based on a literature survey, and Cao et al. (2008), respectively. Based on the field survey, the actual PR
(\%) and PB (\%) in 2011 were calculated using formulas 2 and 3, respectively: 


$$
\begin{aligned}
& P R_{i}=\sum_{j=1}^{M}\left(H A_{i j} \cdot\left(\sum_{k=1}^{F} P R F_{i j k}\right) / F\right) / \sum_{j=1}^{M} H A_{i j} \\
& P B_{i}=\sum_{j=1}^{M}\left(H A_{i j} \cdot\left(\sum_{k=1}^{F} P R F_{i j k}\right) / F\right) / \sum_{j=1}^{M} H A_{i j}
\end{aligned}
$$

where $\mathrm{PRF}_{i j k}$ and $\mathrm{PBF}_{i j k}(\%)$ represent the $\mathrm{PR}$ and $\mathrm{PB}$ for crop $j$ in province $i$ for the $k$ th farmer, $F$ represents the number of surveyed farmers in province $i$ who planted crop $j$, and $M$ represents the number of crop species planted in 2011 in province $i$. The values of PR and PB were between 0 and 100.

\subsubsection{Process}

Five processes of residue retention and burning were involved in the CANM-Straw. (1) Soil C sequestration (SCS). Compared with the SRBM, the CANM-Straw was dependent on the amount of residue-C input rather than the amount of retained residue to linearly determine the soil $\mathrm{C}$ sequestration rate (SCSR). The linear relationships were based on 174 pairs of long-term published experimental data $(P<0.05$, Fig. A1 in the Appendix). (2) Mitigation of $\mathrm{N}$ fertilizer substitution (MNS). The substitution effect from residue-N inputs could avoid GHG emissions from equivalent $\mathrm{N}$ fertilizer production. We adopted an emission factor for GHGs from

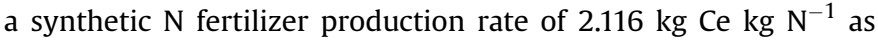
estimated by a life cycle analysis of $\mathrm{N}$ fertilizer production in China (Chen et al., 2015) rather than the value of $1.748 \mathrm{~kg}$ Ce $\mathrm{kg} \mathrm{N}^{-1}$ calculated from fossil fuel combustion or electric power consumption in production processes alone as used in the SRBM (Lu et al., 2010b). (3) Additional fuel consumption for residue retention (ED). After residue retention, additional tilling or ploughing is typically implemented to ensure the sowing quality of the next crop. A field survey of machinery practices indicated that the additional diesel consumption was $31 \mathrm{~kg} \mathrm{ha}^{-1}$ under residue retention compared with $14 \mathrm{~kg} \mathrm{ha}^{-1}$ as used in the SRBM, which was cited from Chen et al. (2008). (4) $\mathrm{CH}_{4}$ emission from rice paddies (EP). The global warming potential (GWP) of $\mathrm{CH}_{4}$ emission was estimated using the method recommended by the IPCC (2006). The emission factors for $\mathrm{CH}_{4}$ were estimated using 272 published data points for $\mathrm{CH}_{4}$ emissions from rice paddies. In addition, the scaling factors of $\mathrm{CH}_{4}$ emissions were linearly determined based on the residue- $C$ inputs from 41 published experimental data pairs $\left(P=0.003\right.$, Fig. $\mathrm{A} 2$ in Appendix). (5) $\mathrm{CH}_{4}$ and $\mathrm{N}_{2} \mathrm{O}$ emissions from residue burning (EB). The total GWP of $\mathrm{CH}_{4}$ and $\mathrm{N}_{2} \mathrm{O}$ emissions from residue burning was estimated using a method recommended by the IPCC (2006). Using the CANM-Straw, the GHG emissions and mitigation potential in five processes were calculated per unit area of cropland. The calculation steps in the CANM-Straw are listed in the Appendix section A.1.

\subsubsection{Output}

As one output of the CANM-Straw, the TEGEs were obtained for the five scenarios of residue retention and burning to estimate the

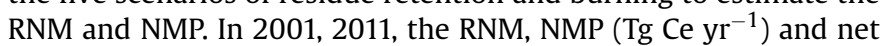
mitigation rate (NMR, $\mathrm{kg} \mathrm{Ce} \mathrm{ha}^{-1} \mathrm{yr}^{-1}$ ) were calculated using formulas 4, 5 and 6 , respectively:

$$
\begin{aligned}
& R N M_{i}=T E G E_{F B i}-T E G E_{C S i} \\
& N M P_{i}=T E G E_{C S i}-T E G E_{F R i}
\end{aligned}
$$

$N M R_{i}=R N M_{i} \cdot 10^{9} /\left(A_{i} \cdot P R_{i} / 100\right)$

where TEGE $E_{C S i}, \mathrm{TEGE}_{F B i}$ and $\mathrm{TEGE}_{F R i}$ represent the TEGEs for the current scenario, the full burning scenario and the full retention scenario for province $i$, respectively.

\subsection{Statistical analysis}

To test the validity of this survey, a paired-sample $t$-test was conducted to test the difference between our survey and the Chinese Statistical Yearbook data (NBS, 2012) for crop yields in 2011. The crops adopted in the $t$-test included only three cereals (rice, wheat and corn) because their harvested area accounted for $81 \%$ of the area of the nine crops. The analysis indicated no significant difference for crop yields between the two data sources $(p=0.288$ for rice in 23 provinces, $p=0.427$ for wheat in 21 provinces and $p=0.091$ for corn in 27 provinces).

\section{Results}

\subsection{Residue retention and burning}

In 2011, the total cropland area for the nine studied crops in China was $81.6 \mathrm{M}$ ha (Table 1 ). The total residue, residue $\mathrm{C}$ and residue $\mathrm{N}$ from the nine crops were $778 \mathrm{Mt}, 273 \mathrm{Mt} \mathrm{C}$ and $5.7 \mathrm{Mt} \mathrm{N}$, respectively. The residue- $C$ on the croplands was $3.5,4.2,3.0$ and $2.8 \mathrm{t} \mathrm{C} \mathrm{ha}^{-1}$ in the northeast, north, northwest and south, respectively. The residue-C exceeded $5 \mathrm{t} \mathrm{C} \mathrm{ha}^{-1}$ in Henan, Shandong and Xinjiang.

In 2001, the percentage of China's croplands implementing residue retention and burning were $28 \%$ and $22 \%$, respectively (Table 2). In 2011, 38\% of China's croplands implemented residue retention, whereas $27 \%$ implemented residue burning. Therefore, residue retention increased to $295 \mathrm{Mt}$ and represented inputs of $103 \mathrm{Mt} \mathrm{C}$ and 2.1 Mt N in 2011. In addition, $200 \mathrm{Mt}$ of residue was still burned on the fields. According to the percentages of residue retention, the cropping regions ranked as north $(62 \%)>$ south $(35 \%)>$ northwest $(23 \%)>$ northeast $(9 \%)$. The four provinces (i.e., Hebei, Shandong, Henan and Shanxi) where more than half of the croplands had implemented residue retention were located in northern China. The amount of burned residue was 98, 61, 40 and $12 \mathrm{Mt}$ in the south, northeast, north and northwest, respectively.

In the full retention scenario, the percentage of croplands implementing residue retention increased to 65\% in China in 2011 (Table 2). According to the percentages, the cropping regions ranked as follows: north $(76 \%)>$ south $(71 \%)>$ northeast $(41 \%)>$ northwest (37\%). Residue retention in China resulted in $173 \mathrm{Mt} C$ input on $50 \mathrm{M}$ ha of croplands. The annual input was more than $10 \mathrm{Tg} \mathrm{C}$ in Shandong, Henan, Hebei, Heilongjiang, Jiangsu and Sichuan. The sum of these inputs represented $53 \%$ of the total input in China.

\subsection{Soil carbon sequestration}

The SCSR in China was 781, 590, 462 and $751 \mathrm{~kg} \mathrm{C} \mathrm{ha}^{-1} \mathrm{yr}^{-1}$ in the northeast, north, northwest and south, respectively (Table 3). The total SCS was $11.7 \mathrm{Tg} \mathrm{C} \mathrm{yr}^{-1}$ in 2001 (Fig. 3) and increased to 19.0 $\mathrm{Tg} \mathrm{C} \mathrm{yr}^{-1}$ in 2011 (Fig. 4). In 2011, the SCS was 1.0, 8.5, 1.0 and 8.5 $\mathrm{Tg} \mathrm{C} \mathrm{yr}^{-1}$ in the northeast, north, northwest and south, respectively. The SCS was over $2 \mathrm{Tg} \mathrm{C} \mathrm{yr}^{-1}$ in Shandong, Henan and Hebei. Therefore, full residue retention would increase the total SCS

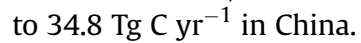


Table 1

Cropland area and crop residue in 2011 in China.

\begin{tabular}{|c|c|c|c|c|}
\hline Cropping region & Province & Croplandarea $\left(10^{3}\right.$ ha $)$ & Residue(t ha $\left.{ }^{-1} \mathrm{yr}^{-1}\right)$ & Residue $-\mathrm{C}\left(\mathrm{t} \mathrm{C} \mathrm{ha} \mathrm{hr}^{-1} \mathrm{yr}^{-1}\right)$ \\
\hline \multirow[t]{3}{*}{ Northeast } & Liaoning & 2886 & 10.7 & 3.75 \\
\hline & Jilin & 4375 & 11.9 & 4.14 \\
\hline & Heilongjiang & 7879 & 8.7 & 3.04 \\
\hline \multirow[t]{7}{*}{ North } & Beijing & 153 & 14.4 & 4.96 \\
\hline & Tianjin & 337 & 9.8 & 3.43 \\
\hline & Hebei & 4594 & 12.3 & 4.27 \\
\hline & Shanxi & 2838 & 7.5 & 2.59 \\
\hline & Inner Mongolia & 4816 & 8.2 & 2.86 \\
\hline & Shandong & 5174 & 14.6 & 5.05 \\
\hline & Henan & 5437 & 15.5 & 5.35 \\
\hline \multirow[t]{5}{*}{ Northwest } & Shaanxi & 2914 & 6.5 & 2.25 \\
\hline & Gansu & 3011 & 4.8 & 1.68 \\
\hline & Qinghai & 363 & 4.5 & 1.61 \\
\hline & Ningxia & 684 & 7.6 & 2.62 \\
\hline & Xinjiang & 3144 & 13.8 & 5.04 \\
\hline \multirow[t]{16}{*}{ South } & Shanghai & 110 & 9.2 & 3.23 \\
\hline & Jiangsu & 3393 & 10.1 & 3.54 \\
\hline & Zhejiang & 984 & 5.9 & 2.12 \\
\hline & Anhui & 4090 & 9.3 & 3.26 \\
\hline & Fujian & 576 & 6.6 & 2.34 \\
\hline & Jiangxi & 2059 & 7.3 & 2.61 \\
\hline & Hubei & 3183 & 9.2 & 3.31 \\
\hline & Hunan & 2663 & 9.7 & 3.47 \\
\hline & Guangdong & 1438 & 6.9 & 2.47 \\
\hline & Guangxi & 2682 & 7.1 & 2.58 \\
\hline & Hainan & 350 & 4.3 & 1.54 \\
\hline & Chongqing & 1215 & 8.3 & 2.94 \\
\hline & Sichuan & 3905 & 9.0 & 3.19 \\
\hline & Guizhou & 2639 & 3.8 & 1.35 \\
\hline & Yunnan & 3647 & 5.8 & 2.05 \\
\hline & Tibet & 101 & 5.2 & 1.83 \\
\hline China & & 81639 & 9.5 & 3.35 \\
\hline
\end{tabular}

Table 2

Percentages of croplands with residue retention (PR) and burning (PB) in 2001 and 2011 in China (\%).

\begin{tabular}{|c|c|c|c|c|c|}
\hline \multirow[t]{2}{*}{ Cropping region } & \multirow[t]{2}{*}{ Province } & \multicolumn{2}{|c|}{2001} & \multicolumn{2}{|c|}{2011} \\
\hline & & PR & PB & PR & PB \\
\hline \multirow[t]{3}{*}{ Northeast } & Liaoning & 31.1 & 21.1 & 11.2 & 30.0 \\
\hline & Jilin & 15.0 & 21.0 & 4.0 & 33.5 \\
\hline & Heilongjiang & 35.1 & 22.4 & 10.2 & 33.2 \\
\hline \multirow[t]{7}{*}{ North } & Beijing & 47.3 & 45.2 & 88.6 & 3.3 \\
\hline & Tianjin & 47.3 & 40.6 & 29.1 & 18.1 \\
\hline & Hebei & 47.3 & 24.2 & 80.8 & 5.8 \\
\hline & Shanxi & 55.7 & 21.0 & 55.5 & 26.3 \\
\hline & Inner Mongolia & 15.0 & 21.3 & 10.7 & 44.5 \\
\hline & Shandong & 23.6 & 26.5 & 77.8 & 4.1 \\
\hline & Henan & 34.6 & 19.7 & 60.8 & 11.7 \\
\hline \multirow[t]{5}{*}{ Northwest } & Shaanxi & 32.0 & 14.8 & 33.2 & 5.2 \\
\hline & Gansu & 26.8 & 16.6 & 13.5 & 16.6 \\
\hline & Qinghai & 15.0 & 10.1 & 0.8 & 25.4 \\
\hline & Ningxia & 7.0 & 20.1 & 30.0 & 41.8 \\
\hline & Xinjiang & 15.0 & 19.2 & 19.3 & 14.1 \\
\hline \multirow[t]{16}{*}{ South } & Shanghai & 47.8 & 48.7 & 47.2 & 38.6 \\
\hline & Jiangsu & 31.9 & 34.2 & 26.8 & 60.6 \\
\hline & Zhejiang & 23.9 & 42.6 & 47.2 & 38.6 \\
\hline & Anhui & 30.3 & 18.7 & 23.6 & 47.3 \\
\hline & Fujian & 35.5 & 32.5 & 26.8 & 47.9 \\
\hline & Jiangxi & 65.1 & 21.7 & 40.0 & 18.9 \\
\hline & Hubei & 38.0 & 23.4 & 28.7 & 41.5 \\
\hline & Hunan & 20.0 & 22.3 & 43.1 & 38.5 \\
\hline & Guangdong & 41.4 & 36.5 & 38.0 & 8.4 \\
\hline & Guangxi & 15.0 & 16.7 & 45.3 & 35.0 \\
\hline & Hainan & 38.0 & 30.2 & 29.1 & 53.6 \\
\hline & Chongqing & 15.0 & 19.4 & 58.0 & 35.7 \\
\hline & Sichuan & 14.3 & 19.9 & 49.7 & 37.8 \\
\hline & Guizhou & 15.0 & 15.0 & 8.0 & 8.1 \\
\hline & Yunnan & 15.0 & 11.4 & 22.0 & 17.4 \\
\hline & Tibet & 15.0 & 8.5 & 0.8 & 24.5 \\
\hline China & & 28.0 & 21.6 & 37.9 & 27.4 \\
\hline
\end{tabular}

\subsection{Mitigation resulting from $N$ fertilizer substitution}

In 2001, 1.2 Mt of $\mathrm{N}$ fertilizer was substituted with residue retention, and this process mitigated $2.5 \mathrm{Tg}^{\mathrm{Ce}} \mathrm{yr}^{-1}$ of GHG emissions (Fig. 3). In 2011, this substitution increased to 2.1 Mt N fertilizer and mitigated $149 \mathrm{~kg} \mathrm{Ce} \mathrm{ha} \mathrm{yr}^{-1}$ on China's croplands (Table 3). In addition, the mitigation was $0.2,2.5,0.3$ and $1.5 \mathrm{Tg} \mathrm{Ce}$ $\mathrm{yr}^{-1}$ in the northeast, north, northwest and south, respectively

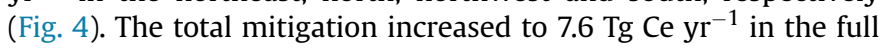
retention scenario. The increase was highest in northeastern China (393\%), whereas the lowest value was observed in northern China (24\%).

\subsection{Additional fossil fuel consumption caused by residue retention}

The additional fuel use associated with residue retention

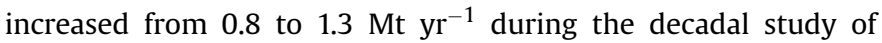
China's croplands. The GHG emissions from these fossil fuels were between 17 and $55 \mathrm{~kg} \mathrm{C} \mathrm{ha}^{-1} \mathrm{yr}^{-1}$ (Table 3). The total emissions were $0.7 \mathrm{Tg} \mathrm{C} \mathrm{yr}^{-1}$ in 2001 (Fig. 3) and increased to $1.1 \mathrm{Tg} \mathrm{C} \mathrm{yr}^{-1}$ in 2011 (Fig. 4). In the full retention scenario, the total emissions from

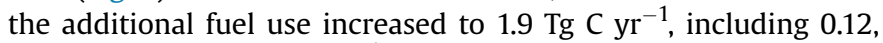

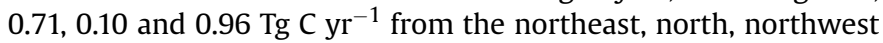
and south, respectively.

\section{5. $\mathrm{CH}_{4}$ emissions from rice paddies}

Compared with rice paddies without residue retention, the $\mathrm{CH}_{4}$ emissions doubled to $2646 \mathrm{~kg} \mathrm{Ce} \mathrm{ha}^{-1} \mathrm{yr}^{-1}$ from paddies with residue retention (Table 3). Rice paddies emitted $49 \mathrm{Tg} \mathrm{Ce}$ of $\mathrm{CH}_{4}$ in 2001 (Fig. 3), and these emissions increased to $53 \mathrm{Tg} \mathrm{Ce}$ of $\mathrm{CH}_{4}$ in 2011 in China (Fig. 4). Furthermore, the emissions increased to

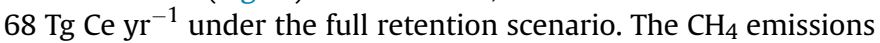


Table 3

Greenhouse gas (GHG) emissions and mitigations in 2011 in China ( $\left.\mathrm{kg} \mathrm{Ce} \mathrm{ha}^{-1} \mathrm{yr}^{-1}\right)$.

\begin{tabular}{|c|c|c|c|c|c|c|c|c|}
\hline \multirow[t]{2}{*}{ Cropping region } & \multirow[t]{2}{*}{ Province } & \multirow[t]{2}{*}{ SCSR } & \multirow[t]{2}{*}{$\mathrm{N}$ fertilizer substitution with $\mathrm{RR}$} & \multicolumn{2}{|c|}{$\begin{array}{l}\text { Avoidance of non- } \mathrm{CO}_{2} \\
\text { GHG emission from } \\
\text { residue burning }\end{array}$} & \multirow[t]{2}{*}{ GHG emission from additional fossil fuel use } & \multicolumn{2}{|c|}{$\begin{array}{c}\text { Seasonal } \mathrm{CH}_{4} \\
\text { emission } \\
\text { from rice } \\
\text { paddy }\end{array}$} \\
\hline & & & & Without RR & With RR & & $\mathrm{CH}_{4}$ & $\mathrm{~N}_{2} \mathrm{O}$ \\
\hline \multirow[t]{3}{*}{ Northeast } & Liaoning & 823 & 168 & 156 & 48 & 21 & 445 & 979 \\
\hline & Jilin & 886 & 184 & 172 & 53 & 20 & 445 & 1062 \\
\hline & Heilongjiang & 707 & 137 & 128 & 39 & 19 & 445 & 940 \\
\hline \multirow[t]{7}{*}{ North } & Beijing & 689 & 210 & 210 & 65 & 55 & 1937 & 3969 \\
\hline & Tianjin & 493 & 153 & 145 & 45 & 35 & 1937 & 4234 \\
\hline & Hebei & 600 & 183 & 183 & 56 & 45 & 1937 & 4160 \\
\hline & Shanxi & 386 & 112 & 109 & 34 & 38 & 1937 & 3545 \\
\hline & Inner Mongolia & 421 & 131 & 120 & 37 & 45 & 1937 & 4530 \\
\hline & Shandong & 700 & 211 & 218 & 67 & 39 & 1937 & 4448 \\
\hline & Henan & 737 & 213 & 234 & 72 & 39 & 1937 & 4210 \\
\hline \multirow[t]{5}{*}{ Northwest } & Shaanxi & 362 & 97 & 97 & 30 & 30 & 445 & 939 \\
\hline & Gansu & 281 & 83 & 72 & 22 & 25 & & \\
\hline & Qinghai & 271 & 81 & 69 & 21 & 22 & & \\
\hline & Ningxia & 414 & 122 & 112 & 35 & 33 & 445 & 1026 \\
\hline & Xinjiang & 760 & 255 & 212 & 66 & 32 & 445 & 1036 \\
\hline \multirow[t]{16}{*}{ South } & Shanghai & 856 & 138 & 143 & 44 & 36 & 1483 & 3412 \\
\hline & Jiangsu & 930 & 147 & 156 & 48 & 40 & 1483 & 3394 \\
\hline & Zhejiang & 586 & 100 & 92 & 28 & 29 & 1445 & 3105 \\
\hline & Anhui & 863 & 135 & 143 & 44 & 43 & 1448 & 2908 \\
\hline & Fujian & 639 & 115 & 102 & 32 & 39 & 1409 & 2803 \\
\hline & Jiangxi & 705 & 122 & 113 & 35 & 42 & 1356 & 2662 \\
\hline & Hubei & 876 & 152 & 142 & 44 & 47 & 1431 & 3209 \\
\hline & Hunan & 914 & 161 & 149 & 46 & 54 & 1378 & 2790 \\
\hline & Guangdong & 670 & 117 & 106 & 33 & 36 & 1338 & 2584 \\
\hline & Guangxi & 697 & 123 & 108 & 33 & 30 & 1345 & 2519 \\
\hline & Hainan & 446 & 73 & 66 & 20 & 23 & 1351 & 2408 \\
\hline & Chongqing & 785 & 144 & 125 & 39 & 51 & 1483 & 3173 \\
\hline & Sichuan & 845 & 145 & 137 & 42 & 51 & 1482 & 3256 \\
\hline & Guizhou & 399 & 70 & 57 & 18 & 40 & 1483 & 2625 \\
\hline & Yunnan & 570 & 98 & 87 & 27 & 39 & 1471 & 2956 \\
\hline & Tibet & 517 & 69 & 81 & 25 & 17 & 1483 & 2934 \\
\hline China & & 675 & 149 & 143 & 44 & 36 & 1281 & 2646 \\
\hline
\end{tabular}

SCSR, soil carbon sequestration rate; RR, residue retention. Note: no rice was planted in Gansu and Qinghai in 2011.

in southern China accounted for $90 \%$ of the total emissions in China under all scenarios (Figs. 3 and 4). The $\mathrm{CH}_{4}$ increase in south China also played a dominant role in the overall increase throughout China.

\subsection{GHG emissions from residue burning}

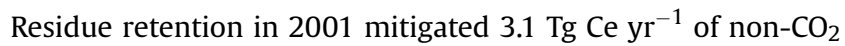
GHG emissions (including $\mathrm{CH}_{4}$ and $\mathrm{NO}_{2}$ ) from residue burning in the full burning simulation (Fig. 3). This mitigation was $5.8 \mathrm{Tg} \mathrm{Ce}$

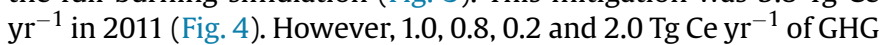
emissions in 2011 occurred in the northeastern, northern, northwestern and southern China, respectively. Therefore, mitigation

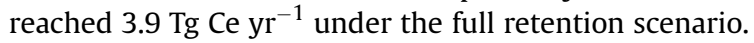

\subsection{Net GHG mitigation from residue retention}

Residue retention in place of burning induced different effects on the NMR across the 31 provinces (Fig. $5 a$ and b). The average NMR in China was $250 \mathrm{~kg} \mathrm{Ce} \mathrm{ha}^{-1}$ in 2001 (Fig. 5a), which increased to $480 \mathrm{~kg} \mathrm{Ce} \mathrm{ha}^{-1}$ in 2011 (Fig. 5b). In addition, the NMR values changed from negative to positive in Hubei, Guangxi and Chongqing. However, the NMR changed from positive to negative in Jiangsu. In 2011, five provinces (Liaoning, Jilin, Beijing, Shandong and Xinjiang) had NMRs $>1000 \mathrm{~kg} \mathrm{Ce} \mathrm{ha}^{-1} \mathrm{yr}^{-1}$ among the 23 provinces with positive NMRs. In addition, the NMRs from eight provinces in south China (Shanghai, Jiangsu, Zhejiang, Fujian, Jiangxi, Hunan, Guangdong and Hainan) were negative.

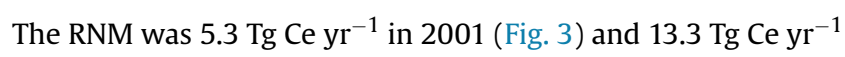
in 2011 for Chinese croplands (Fig. 4). The RNM in northern China increased by 1.5 fold, which explained $95 \%$ of the increase in the total RNM in China from 2001 to 2011. However, the RNM decreased by $43 \%$ and $28 \%$ in the northeast and south, respectively. Compared with 2011, a full extension of residue retention could

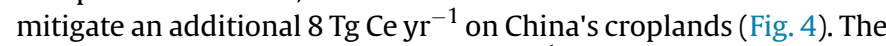

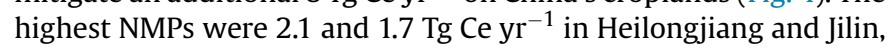
respectively. Moreover, the maximum total NMP would be $10 \mathrm{Tg} \mathrm{Ce}$ $\mathrm{yr}^{-1}$ if residue retention was not implemented in the eight provinces with negative NMRs.

\section{Discussion}

\subsection{Residue retention and burning}

Residues from the nine studied crops increased from $553 \mathrm{Mt}$ in 2001 to $778 \mathrm{Mt}$ in 2011 on China's croplands. A residue increase was also observed from 2000 to 2009 (Jiang et al., 2012) as a result of a gradual increase in crop productivity (Huang et al., 2007). However, the percentage of biomass fuel consumption in the total rural energy consumption decreased by $4 \%$ from 2001 to 2008 (Yao et al., 2012). This drop was attributed to the economic advancement of farmers (Cao et al., 2008) and the popularization of fossil fuel use (such as coal and natural gas). Hence, the use of residue required management before the next crop could be sown.

In this study, the PR increased from $28 \%$ to $38 \%$ from 2001 to 2011 (Table 2). In addition, the amount of residue retention 


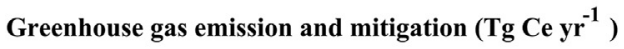

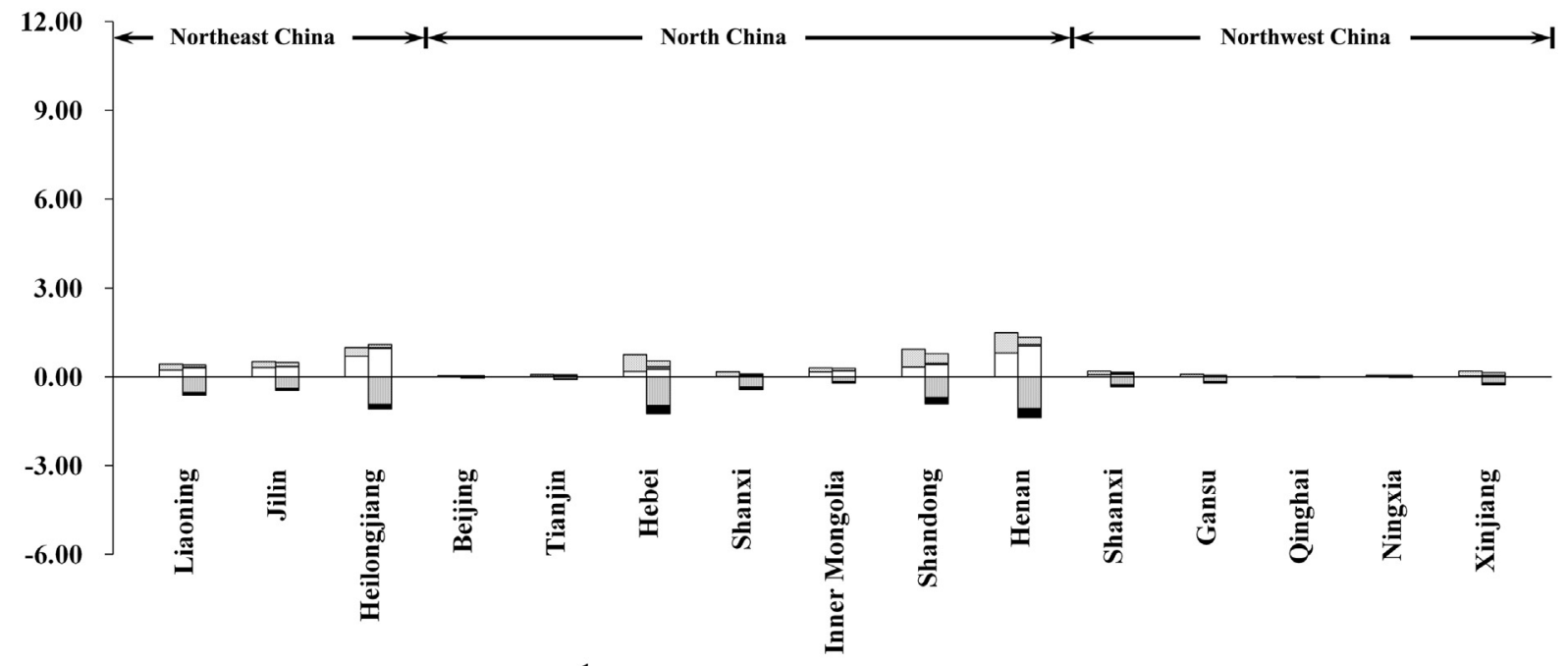

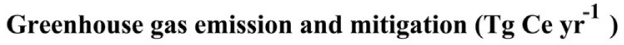

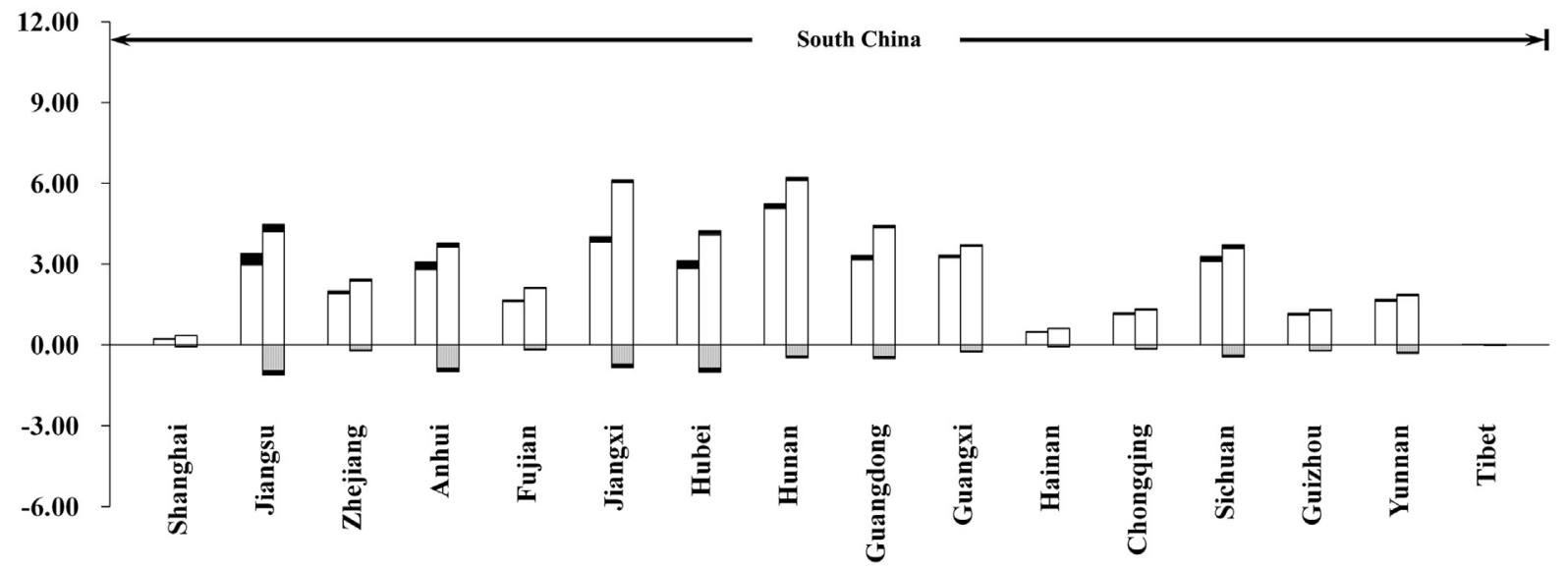

$\square$ SCS $\square$ MNS $\square$ EP $\square$ ED $\square$ EB

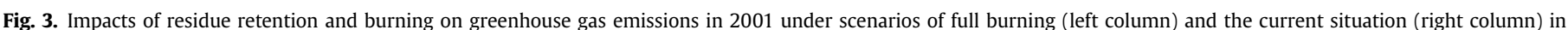

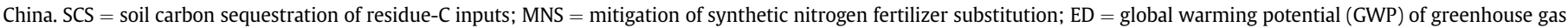

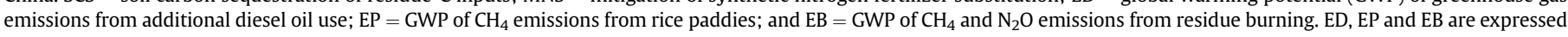
as positive values, whereas SCS and MNS are expressed as negative values.

increased from 144 (Lu et al., 2010b) to $295 \mathrm{Mt} \mathrm{yr}^{-1}$. The increases in Shandong, Henan and Hebei accounted for $73 \%$ of the total increases in China. However, the increase in residue productivity and decrease in residue used as fuel also enhanced the amount of residue burning on croplands. The total burned residue increased from $140 \mathrm{Mt}$ in 2000 (Cao et al., 2008) to $200 \mathrm{Mt}$ in 2011 (this study). Bao et al. (2014) reported that the percentage of burned residue was $12 \%$ in northwestern China, which was similar to the level in our survey (14\%). The status and trend of residue burning implied the potential for extending residue retention on Chinese croplands.

\subsection{Soil carbon sequestration}

SOC dynamics are typically driven by anthropogenic forces rather than by climate change (Lugato et al., 2014). China's agricultural soils lost $30 \%-50 \%$ of the antecedent SOC pool, which was partly a result of soil mismanagement (Lal, 2004b). Under less residue retention, the results of the DNDC model indicated a soil C loss of 79-95 $\mathrm{Tg} \mathrm{C} \mathrm{yr}^{-1}$ in the 1990s from China's croplands (Li et al.,
2003; Tang et al., 2006). Qin et al. (2013) estimated that the total SCS potential was $2.7 \mathrm{Pg} \mathrm{C}$ before a saturated SOC level was reached. If residue retention in the provinces with positive NMRs was maintained for approximately 20 years, as assumed in the present study, then the total SCS (0.58 Pg C) would make an important contribution to increasing the SOC content of China's croplands and could achieve approximately $20 \%-26 \%$ of the SCS potential of 2.21-2.95 Pg C before reaching the C-saturation level (Cheng et al., 2014). Under residue retention increases of $15 \%-30 \%$, the SCS was 3.6 $\mathrm{Tg} \mathrm{C} \mathrm{yr}^{-1}$ in 2008 (Lun et al., 2016), whereas under residue retention increases of $28 \%$ in 2001 to $38 \%$ in 2011 (this study), it was

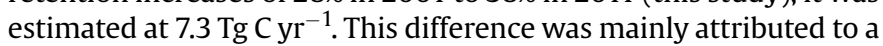
residue retention increase of $91 \mathrm{Mt}$ in the former study and $151 \mathrm{Mt}$ in this study. Wu et al. (2015) reported that the factor with the most significant impact on SOC change was residue management (49.4\%), followed by $\mathrm{CO}_{2}$ enrichment (37\%), tillage $(6.2 \%)$ and fertilizer (1.6\%) in a study from Iowa in the United States of America. Therefore, residue retention could be regarded as one of the most direct and promising contributions to soil C stocks on croplands ( $\mathrm{Lu}$ 


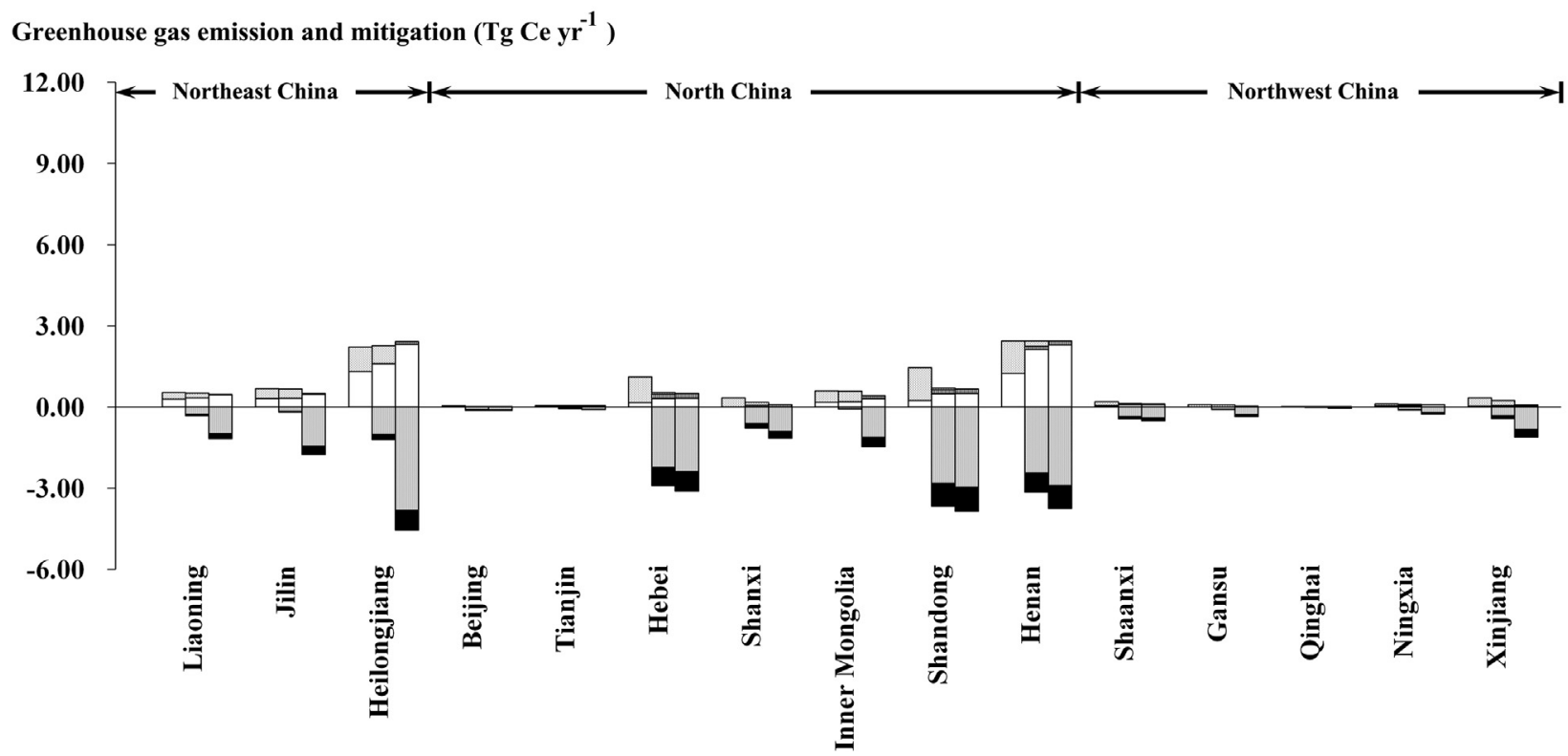

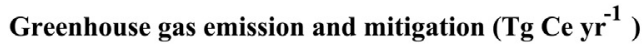

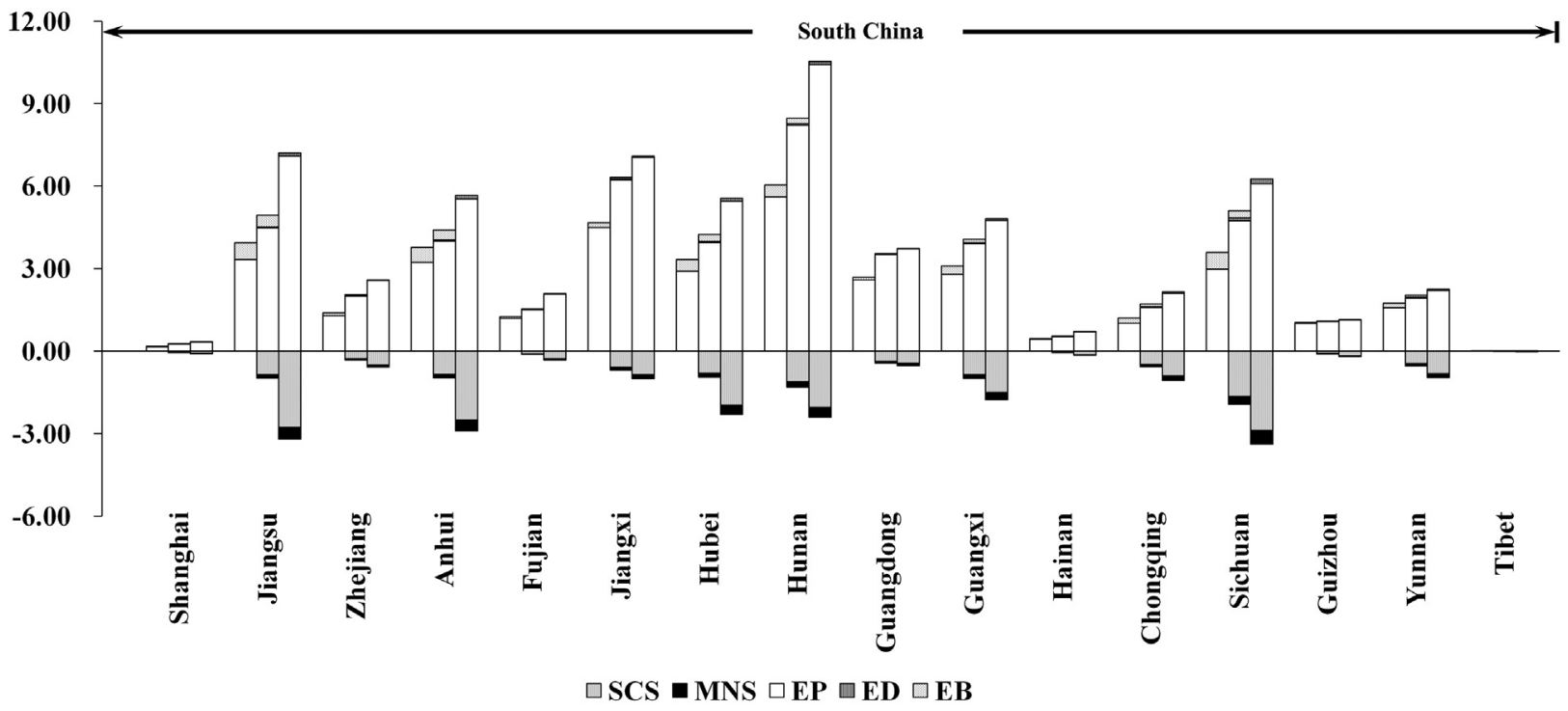

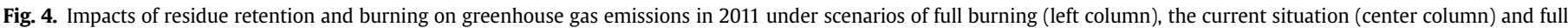

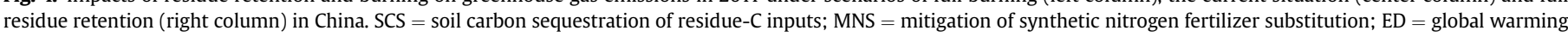

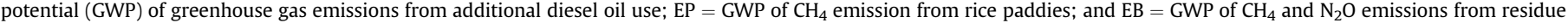
burning. ED, EP and EB are expressed as positive values, whereas SCS and MNS are expressed as negative values.

\section{et al., 2009).}

In this study, the temporal dynamics of SCS were primarily attributed to changes in the crop yield and the cropland area under residue retention. For instance, over the studied decade, the residue retention area increased from 86 to $262 \%$, and the crop yields increased by $17-42 \%$ in Shandong, Henan, Hebei and Sichuan (NBS, 2012). These changes increased the SCS by more than $1 \mathrm{Tg} \mathrm{Ce}$ in each province. However, although the crop yield increased in Jilin (70\%) and Liaoning (53\%) (NBS, 2012), the SCS decreased by approximately one-half because of decreases in residue retention of more than 60\% from 2001 (Lu et al., 2010b) to 2011 in the two provinces studied. The amounts of SCS were determined by both the crop yield and cropland area under residue retention.

\subsection{Mitigation of $N$ fertilizer substitution}

The substitution effect from residue retention depends on the implementation of precision fertilization on croplands (Lu et al., 2010a). In the present study, the mitigation resulting from the substitution of $\mathrm{N}$ fertilizer could contribute to $30 \%$ of the total NMP in the full retention scenario for 2011. However, under excessive $\mathrm{N}$ fertilization, residue $\mathrm{N}$ would increase the additional soil $\mathrm{N}_{2} \mathrm{O}$ emissions and result in soil acidification (Ju et al., 2009). Therefore, the extension of residue retention on China's croplands should be implemented together with improvements in fertilizer management (Li et al., 2003). 

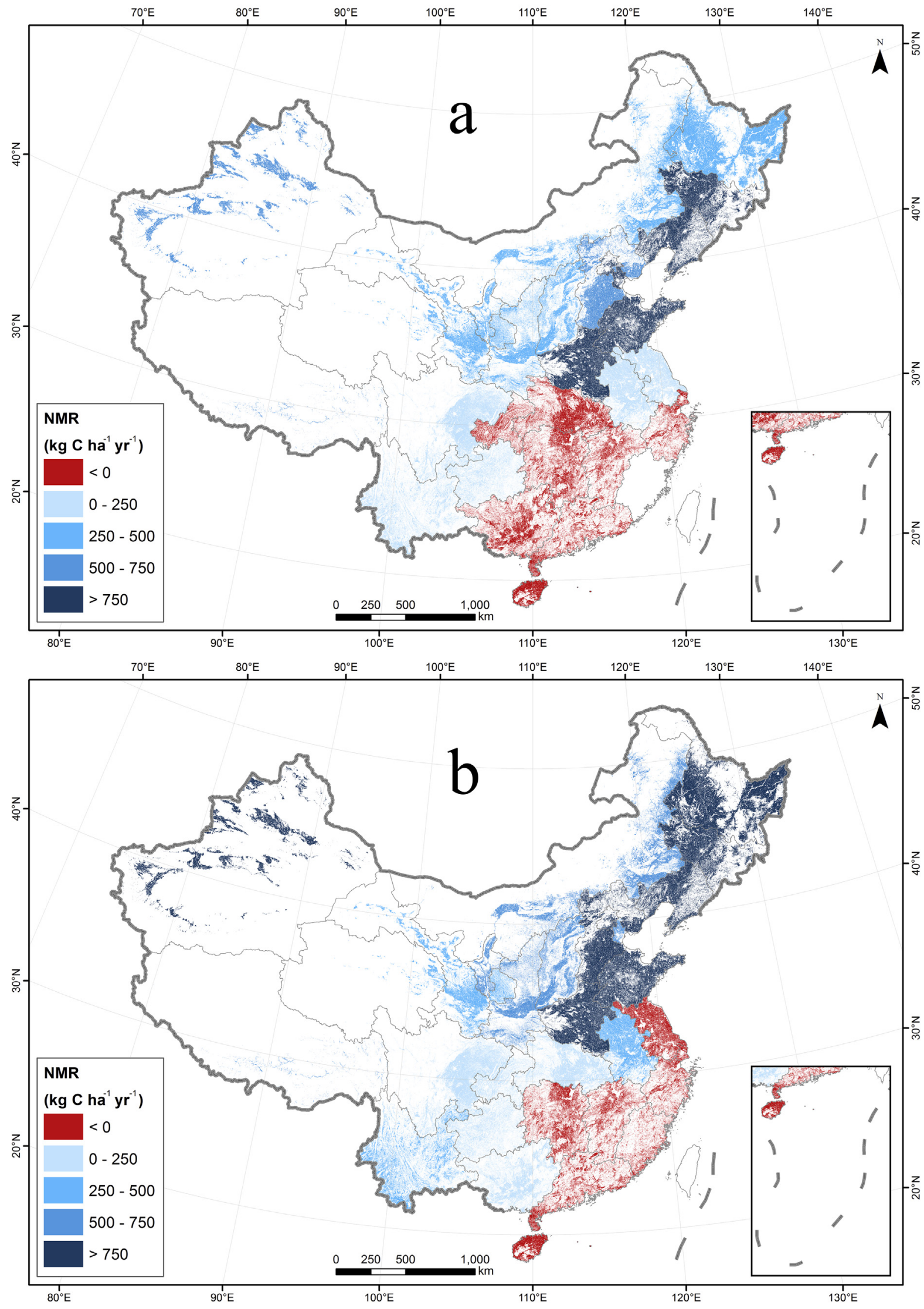

Fig. 5. Net mitigation rate (NMR) from residue retention in place of burning on China's croplands in 2001 (a) and 2011 (b). 


\subsection{Additional fossil fuels used for residue retention}

The results of the residue retention scenarios indicate that diesel consumption increased from 0.8 to $1.3 \mathrm{Mt} \mathrm{yr}^{-1}$ on Chinese croplands during the study decade. This consumption would increase by

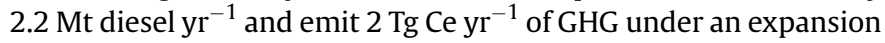
of residue retention. However, these emissions could be reduced by reducing tillage or with no-till practices. Dikgwatlhe et al. (2014) implied that under no-till, more $\mathrm{C}$ would be sequestered compared with plow tillage on croplands with residue retention on the North China Plain. The additional diesel consumption had a relatively low contribution to GHG emissions but increased the economic cost for farmers. Suitable tillage practices could promote the extension of residue retention in China's croplands.

\section{5. $\mathrm{CH}_{4}$ emissions from rice paddies}

Residue retention increases the $\mathrm{CH}_{4}$ emission from rice paddies in China. These additional $\mathrm{CH}_{4}$ emissions offset $96 \%, 78 \%$ and $84 \%$ of the total SCS from residue retention in the actual scenarios during 2001, 2011 and the full retention scenario, respectively, and even reached $156 \%$ of the SCS in southern China in 2011. Hence, these emissions were the greatest GHG leakage factor under all scenarios. The spatio-temporal variation of $\mathrm{CH}_{4}$ emissions increases were attributed to two factors: the amount of residue retained in rice paddies and the area of paddy rice using residue retention. The increases in residue retention enhanced the $\mathrm{CH}_{4}$ emissions from paddies in Hunan and Sichuan by 2.12 and $1.16 \mathrm{Tg}$ Ce, respectively. However, the $\mathrm{CH}_{4}$ emission increased $(0.51 \mathrm{Tg} \mathrm{Ce})$ in Heilongjiang was mainly attributed to the expansion of rice paddies (88\%) (NBS, 2012). The total rice paddy area accounted for $48 \%$ of the harvested area of the nine crops in southern China and reached $67 \%$ in the eight provinces that exhibited negative NMRs in this study. Hence, the negative NMRs were mainly caused by the increase in $\mathrm{CH}_{4}$ emissions in these provinces.

The implementation of suitable practices can promote SCS or limit $\mathrm{CH}_{4}$ emissions from rice paddies. For example, residue retention together with mineral fertilization in paddies could extend the duration of $C$ sequestration and double the SCS potential compared with mineral fertilization alone (Tian et al., 2015). Zhang et al. (2014) also indicated that a reduction in C inputs during the rice season along with improvements in N-use efficiency to $40 \%$

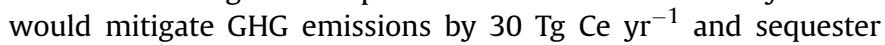
$22 \mathrm{Tg} \mathrm{C} \mathrm{yr}^{-1}$ in China's rice paddies. Moreover, optimized irrigation patterns, such as changing from continuous flooding to intermittent flooding, would greatly reduce the $\mathrm{CH}_{4}$ emissions from rice paddies (Wang et al., 2012). Therefore, retaining residue under proper circumstances and with suitable water management favors $\mathrm{CH}_{4}$ emission mitigation in China's rice paddies under the expansion of residue retention.

\subsection{GHG emissions from residue burning}

Agricultural biomass burning led to substantial GHG emission and accounted for $12 \%$ of the GWP from global agricultural non- $\mathrm{CO}_{2}$ GHG emissions (Smith, 2012). Compared with the conditions one decade ago (Lu et al., 2010a), the GHG emissions from residue burning increased by $78 \%$ in this study as a result of increases in residue production and residue burning. However, these emissions decreased in Shandong, Hebei and Henan in 2011 compared with the levels in 2000 (Cao et al., 2008). Our results also indicated that the emissions decreased as a result of residue retention in place of burning in these provinces from 2001 to 2011. The sum of GHG emissions from northeastern and southern China accounted for $74 \%$ of the total emissions from residue burning. Residue burning not only increases GHG emissions but also reduces crop yields and increases soil erosion (Smith et al., 2012). Furthermore, residue burning is one of the main contributing factors to air pollution during harvest periods in China (Hong et al., 2016). The expansion of residue retention could overcome these disadvantages resulting from of residue burning.

\subsection{Net GHG mitigation from residue retention}

In this study, the variability in the RNM indicated spatial heterogeneity caused by changes in crop types and residue management. In northeastern China, the decrease in RNM was mainly attributed to the increased rice paddy area (NBS, 2012) and the decreased residue retention. The increase in RNM in northern China represented 95\% of China's overall increase because the residue retention increased by 1.6 fold over the 10 -year period. In northwestern China, the increase in SCS represented $64 \%$ of the total increase in RNM. The paddy area decreased by $0.4 \mathrm{M}$ ha (NBS, 2012), which reduced the additional net GHG emission from residue retention in southern China. This decrease in paddy area also changed the values of RNM from negative to positive in Guangxi and Chongqing. In addition, the RNM changed from negative to positive in Hubei, which was mainly due to the decrease in paddy area with residue retention. However, the paddy area increased by $12 \%$ in Jiangsu (NBS, 2012); hence, residue retention, which was performed to mitigate GHGs in 2001, led to more GHG emissions in 2011.

The $\mathrm{C}$ and $\mathrm{N}$ processes other than $\mathrm{C}$ sequestration affected the contribution of residue retention to GHG mitigation. Compared with the upland areas, the paddy area had a higher SCS potential in China (Qin et al., 2013) and a faster recovery rate of SOC level due to residue retention in northeastern China (Ouyang et al., 2014). However, our results indicate that the $\mathrm{CH}_{4}$ emissions from paddies would exceed the SCS and lead to negative NMRs under the implementation of residue retention in the eight provinces. The net GHG mitigation of other SCS practices may also be affected by changes in fuel consumption and non- $\mathrm{CO}_{2}$ GHG emissions (Lal, 2004a). For instance, the SCS of $\mathrm{N}$ fertilization could be fully offset by the considerable GHG emissions from fertilizer production and enhanced soil $\mathrm{N}_{2} \mathrm{O}$ emissions (Lu et al., 2008; Schlesinger, 2010). The SCS from no-till practices would also be partially counteracted by increased $\mathrm{N}_{2} \mathrm{O}$ emissions (Powlson et al., 2011). Thus, the full GHG budget of $\mathrm{C}$ and $\mathrm{N}$ cycles in these practices must be considered rather than the dynamics of soil $\mathrm{C}$ stock alone.

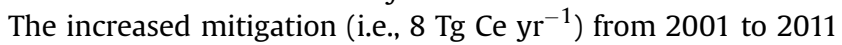
may persist for $10-20$ years, with 20 years representing the time at which soil $\mathrm{C}$ becomes saturated. The NMP under full retention would also function for approximately two decades. These values would generate a total net GHG mitigation of 320-400 Tg Ce in the future. After soil $\mathrm{C}$ saturation, the relatively persistent mitigation from synthetic $\mathrm{N}$ substitution and the avoidance of non- $\mathrm{CO}_{2} \mathrm{GHG}$ emissions from residue burning would still contribute to climate change mitigation, although the net mitigation might be much smaller. Therefore, residue retention has substantial GHG mitigation potential for China's croplands and could represent a "buying time" measure to allow for the development of more permanent mitigation approaches (Lu et al., 2010b).

\subsection{Limitations and suggestions}

In this study, the insignificant difference between the survey data and the statistical data supported the validity of our survey to an extent; however, certain limitations were observed. First, 
although the survey samples covered the main cropping regions of China, the sample size remained a considerable challenge because huge spatial heterogeneity occurs in residue management in China. To address this challenge, a larger-scale or national-scale survey is needed in the future. Second, the questionnaires related to rice, wheat and corn represented $89 \%$ of the total questionnaires. Residue retention from these three crops was more popular compared with the other crops due to highly developed retention technology (NBS, 2012). Hence, our results might slightly overestimate the percentage of croplands using residue retention. However, an areaweighted averaging method was adopted at the provincial level to reduce the uncertainties in the estimations. Lastly, due to spatial heterogeneity and data availability, we expect that more long-term data of residue retention will be available to validate the model in the future.

The extension of residue retention requires governmental promotion and farmer support. Therefore, certain details on expanding residue retention require further attention: (1) residue retention should differentially expand due to the spatial heterogeneity in climate, soil and cropping systems in China; (2) residue retention should be preferably implemented with other suitable practices, including precision fertilization, no-till practices, suitable water management and rice varieties that have low $\mathrm{CH}_{4}$ emission; and (3) the government should compensate farmers for the economic costs of residue retention. In summary, crop residue retention should be prioritized among residue management strategies to meet global food demands (Lal, 2009).

\section{Conclusions}

In this work, a field survey for farmers throughout China was conducted from 2012 to 2013, and a CANM-Straw was developed to estimate the GHG emission changes and mitigation potential of residue retention and burning from 2001 to 2011. Over the studied decade, the residue retention increased from 144 to $295 \mathrm{Mt}$, which accounted for C inputs of $103 \mathrm{Mt}$; however, $200 \mathrm{Mt}$ of residue was still burned on China's croplands in 2011. Although the RNM

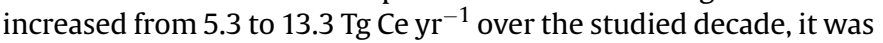
$55 \%$ and 30\% lower than the SCS in 2001 and 2011, respectively. The

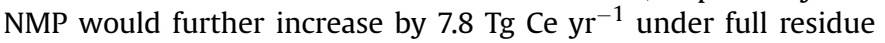
retention expansion in place of residue burning in China. This expansion would lead to negative NMRs as a result of the increase in $\mathrm{CH}_{4}$ emissions from rice paddies in the eight provinces in southern China. Hence, expansion in the remaining 23 provinces

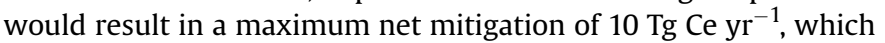
would offset $0.5 \%$ of the $\mathrm{CO}_{2}$ emissions from fossil fuel combustion that occurred in China in 2011 (IEA, 2013). Substantial mitigation potential for China's croplands exists in the targeted expansion of residue retention. Our study outlined the GHG budgets related to crop residue retention and burning in 2001 and 2011 and clarified the effect of spatio-temporal patterns on GHG emissions and mitigation, thereby providing a potential strategy for improving agriculture residue management and mitigating climate change.

\section{Acknowledgments}

This study was supported by National Key R\&D Program of China (2017YFA0604702), National Natural Science Foundation of China (71003092), Strategic Priority Programme of Chinese Academy of Sciences (XDA05050602 and XDA05060102) and the Youth Innovation Promotion Association CAS. We would like to acknowledge Chunyan Zheng, Yi Wang and Yufei Li for assisting in this national scale survey. We thank the students of China Agriculture University for taking part in this survey.

\section{Appendix A. Supplementary data}

Supplementary data related to this article can be found at http:// dx.doi.org/10.1016/j.jclepro.2017.07.077.

\section{References}

Bao, J., Jihua, Y., Feng, Z., Chen, B., Cheng, L., Yang, J., 2014. Situation of distribution and utilization of crop straw resources in seven western provinces, China. Chin. J. Appl. Ecol. 25, 181-187 (in Chinese).

Cao, G., Zhang, X., Wang, Y., Zheng, F., 2008. Estimation of emissions from field burning of crop straw in China. Chin. Sci. Bull. 784-790.

Chen, P., Wang, X., Wang, L., 2008. Carbon Budget and its Sink Promotion of Terrestrial Ecosystem in China, first ed. Science Press, Beijing, China (in Chinese).

Chen, S., Lu, F., Wang, X., 2015. Estimation of greenhouse emission factors of China's nitrogen, phosphate and potash fertilizers. Acta Ecol. Sin. 35, 1-19 (in Chinese).

Cheng, K., Ogle, S.M., Parton, W.J., Pan, G., 2014. Simulating greenhouse gas mitigation potentials for Chinese croplands using the DAYCENT ecosystem model. Glob. Change Biol. 20, 948-962.

Dikgwatlhe, S.B., Chen, Z.-D., Lal, R., Zhang, H.-L., Chen, F., 2014. Changes in soil organic carbon and nitrogen as affected by tillage and residue management under wheat-corn cropping system in the North China plain. Soil Till. Res. 144, $110-118$.

Gentile, R., Vanlauwe, B., van Kessel, C., Six, J., 2009. Managing N availability and losses by combining fertilizer-N with different quality residues in Kenya. Agr. Ecosyst. Environ. 131, 308-314.

Hong, J., Ren, L., Hong, J., Xu, C., 2016. Environmental impact assessment of corn straw utilization in China. J. Clean. Prod. 112, 1700-1708.

Huang, Y., Zhang, W., Sun, W., Zheng, X., 2007. Net primary production of Chinese croplands from 1950 to 1999. Ecol. Appl. 17, 692-701.

Houghton, R., 2002. Temporal patterns of land-use change and carbon storage in China and tropical Asia. Sci. China Ser. C Life Sci. Engl. Ed. 45, 10-17.

International Energy Agency (IEA), 2013. $\mathrm{CO}_{2}$ emissions from fuel combustionhighlights. http://www.iea.org/publications/freepublications/publication/ co2emissionsfromfuelcombustionhighlights2013.pdf (Accessed 30 September 2015).

IPCC, 2006. Guidelines for National Greenhouse Gas Inventories. Institute for Global Environmental Strategies (IGES), Hayama, Japan.

Jiang, D., Zhuang, D., Fu, J., Huang, Y., Wen, K., 2012. Bioenergy potential from crop residues in China: availability and distribution. Renew. Sust. Energ. Rev. 16, 1377-1382.

Jin, V., Baker, J., Johnson, J.F., Karlen, D., Lehman, R.M., Osborne, S., Sauer, T., Stott, D., Varvel, G., Venterea, R., Schmer, M., Wienhold, B., 2014. Soil greenhouse gas emissions in response to corn stover removal and tillage management across the US Corn Belt. Bioenerg. Res. 7, 517-527.

Ju, X., Xing, G., Chen, X., Zhang, S., Zhang, L., Liu, X., Cui, Z., Yin, B., Christie, P., Zhu, Z., Zhang, F., 2009. Reducing environmental risk by improving $\mathrm{N}$ management in intensive Chinese agricultural systems. P. Natl. Acad. Sci. U. S. A. 106 3041-3046.

Lal, R., 2004a. Soil carbon sequestration impacts on global climate change and food security. Science 304, 1623-1627.

Lal, R., 2004b. Offsetting China's $\mathrm{CO}_{2}$ emissions by soil carbon sequestration. Clim. Change 65, 263-275.

Lal, R., 2009. Soil quality impacts of residue removal for bioethanol production. Soil Till. Res. 102, 233-241.

Li, C., Zhuang, Y., Frolking, S., Galloway, J., Harriss, R., Moore III, B., Schimel, D., Wang, X., 2003. Modeling soil organic carbon change in croplands of China. Ecol. Appl. 13, 327-336.

Liu, C., Lu, M., Cui, J., Li, B., Fang, C., 2014. Effects of straw carbon input on carbon dynamics in agricultural soils: a meta-analysis. Glob. Change Biol. 20, $1366-1381$.

Lu, F., Wang, X., Han, B., Ouyang, Z., Duan, X., Zheng, H., 2008. Assessment on the availability of nitrogen fertilization in improving carbon sequestration potential of China's cropland soil. Chin. J. Appl. Ecol. 19, 2239-2250 (in Chinese).

Lu, F., Wang, X., Han, B., Ouyang, Z., Zheng, H., 2010a. Modeling the greenhouse gas budget of straw returning in China. Ann. Ny. Acad. Sci. 1195, E107-E130.

Lu, F., Wang, X., Han, B., Ouyang, Z., Duan, X., Zheng, H., 2010b. Net mitigation potential of straw return to Chinese cropland: estimation with a full greenhouse gas budget model. Ecol. Appl. 20, 634-647.

Lu, F., Wang, X., Han, B., Ouyang, Z., Duan, X., Zheng, H., Miao, H., 2009. Soil carbon sequestrations by nitrogen fertilizer application, straw return and no-tillage in China's cropland. Glob. Change Biol. 15, 281-305.

Lugato, E., Panagos, P., Bampa, F., Jones, A., Montanarella, L., 2014. A new baseline of organic carbon stock in European agricultural soils using a modelling approach. Glob. Change Biol. 20, 313-326.

Lun, F., Canadell, J.G., He, L., Yang, B., Liu, M., Yuan, Z., Tian, M., Liu, J., Li, W., 2016. Estimating cropland carbon mitigation potentials in China affected by three improved cropland practices. J. Mt. Sci. 13, 1840-1854.

Ministry of Agriculture of the People's Republic China (MOA), 2007. The promotion of the integral utilization of crop residue and prohibiting residue burning. http://www.moa.gov.cn/zwllm/zxfb/201007/t20100702_1592877.htm (in Chinese, Accessed 30 September 2015). 
Ministry of Environmental Protection of the People's Republic China (MEP), 1999. Measures on prohibition of crop residue burning and comprehensive use of residue. http://www.zhb.gov.cn/info/gw/huanfa/199904/t19990412_78683.htm (in Chinese, Accessed 30 September 2015).

National Bureau of Statistics of China (NBS), 2012. China Statistical Yearbook, Electronic Edn. China Statistics Press, Beijing, China.

Ouyang, W., Shan, Y., Hao, F., Lin, C., 2014. Differences in soil organic carbon dynamics in paddy fields and drylands in northeast China using the CENTURY model. Agr. Ecosyst. Environ. 194, 38-47.

Petersen, B.M., Knudsen, M.T., Hermansen, J.E., Halberg, N., 2013. An approach to include soil carbon changes in life cycle assessments. J. Clean. Prod. 52, 217-224.

Powlson, D.S., Whitmore, A.P., Goulding, K.W.T., 2011. Soil carbon sequestration to mitigate climate change: a critical re-examination to identify the true and the false. Eur. J. Soil Sci. 62, 42-55.

Oin, Z., Huang, Y., Zhuang, Q., 2013. Soil organic carbon sequestration potential of cropland in China. Global Biogeochem. Cy. 27, 711-722.

Schlesinger, W.H., 2010. On fertilizer-induced soil carbon sequestration in China's croplands. Glob. Change Biol. 16, 849-850.

Shi, T., Liu, Y., Zhang, L., Hao, L., Gao, Z., 2014. Burning in agricultural landscapes: an emerging natural and human issue in China. Landsc. Ecol. 1-14.

Smith, P., 2012. Agricultural greenhouse gas mitigation potential globally, in Europe and in the UK: what have we learnt in the last 20 years? Glob. Change Biol. 18, 35-43.

Smith, W.N., Grant, B.B., Campbell, C.A., McConkey, B.G., Desjardins, R.L., Kröbel, R., Malhi, S.S., 2012. Crop residue removal effects on soil carbon: measured and inter-model comparisons. Agr. Ecosyst. Environ. 161, 27-38.

Tang, H., Qiu, J., Van Ranst, E., Li, C., 2006. Estimations of soil organic carbon storage in cropland of China based on DNDC model. Geoderma 134, 200-206.

Tian, H., Xu, X., Lu, C., Liu, M., Ren, W., Chen, G., Melillo, J., Liu, J., 2011. Net exchanges of $\mathrm{CO}_{2}, \mathrm{CH}_{4}$, and $\mathrm{N}_{2} \mathrm{O}$ between China's terrestrial ecosystems and the atmosphere and their contributions to global climate warming. J. Geophys. Res. 116 G02011.

Tian, K., Zhao, Y., Xu, X., Hai, N., Huang, B., Deng, W., 2015. Effects of long-term fertilization and residue management on soil organic carbon changes in paddy soils of China: a meta-analysis. Agr. Ecosyst. Environ. 204, 40-50.

Wang, J., Zhang, X., Xiong, Z., Khalil, M.A.K., Zhao, X., Xie, Y., Xing, G., 2012. Methane emissions from a rice agroecosystem in South China: effects of water regime, straw incorporation and nitrogen fertilizer. Nutr. Cycl. Agroecosys. 93, 103-112.

Wu, Y., Liu, S., Tan, Z., 2015. Quantitative attribution of major driving forces on soil organic carbon dynamics. JAMES 7 (1), 21-34.

Yao, C., Chen, C., Li, M., 2012. Analysis of rural residential energy consumption and corresponding carbon emissions in China. Energy Pol. 41, 445-450.

Zhang, G., Wang, X., Sun, B., Zhao, H., Lu, F., Zhang, L., 2016. Status of mineral nitrogen fertilization and net mitigation potential of the state fertilization recommendation in Chinese cropland. Agr. Syst. 146, 1-10.

Zhang, W., Yu, Y., Li, T., Sun, W., Huang, Y., 2014. Net greenhouse gas balance in China's croplands over the last three decades and its mitigation potential. Environ. Sci. Technol. 48, 2589-2597.

Zhao, H., Sun, B., Lu, F., Wang, X., Jiang, L., Ouyang, Z., 2014. How can straw incorporation management impact on soil carbon storage? A meta-analysis. Mitig. Adapt. Strat. GL. 1-24. 